\title{
Sistema Acusatório Princípio Processual Penal Implícito na Constituição
}

\section{Adversarial System Principle of Implicit Criminal Procedure in the Constitution}

\author{
Paulo Sérgio Garcia
}

Universidade Estadual de Londrina, Programa de Pós-Graduação Stricto Sensu em Direito Negocial. PR, Brasil.

E-mail: sergiogarcia.facu@hotmail.com

\begin{abstract}
Resumo
O artigo em questão propôs abordar sobre o sistema acusatório princípio processual penal implícito na Constituição Federal e a forma de ser interpretado na Constituição Federal de 1988 pelos doutrinadores. O sistema processual brasileiro apresenta como características seus traços inquisitórios, acusatórios e o misto. $\mathrm{O}$ inquisitivo é um sistema pelo qual as duas funções de acusação e julgamento se apresentam unidas em um único órgão ou em uma única pessoa, e o sistema acusatório, os papéis são reservados para pessoas ou órgãos distintos. No entanto, como observado na literatura, são apresentados conflitos na forma de interpretação dos sistemas. Muitos autores expressam suas posições, uns sustentam que o sistema adotado no Brasil é o inquisitório, outros apontam ser um sistema misto, mas outros afirmam ser o sistema acusatório. Infelizmente, o que se observa através das várias interpretações apresentadas sobre o sistema acusatório, é que este continua preso às amarras do inquisitorialismo. Nestes últimos anos, verifica-se que vêm sendo travadas lutas doutrinárias incessantes, pois se percebe a grande necessidade de transformações, que se tornam urgentes. Estas lutas têm propósitos importantes, objetivam a busca da afirmação de um direito processual penal que seja pautado pela conformidade constitucional.
\end{abstract}

Palavras-chave: Constituição. Princípio Processual. Sistema Acusatório.

\begin{abstract}
The article in question proposed to address the implicit principle in the Constitution adversarial system of criminal procedure and the way it is interpreted in the Federal Constitution of 1988 by the jurists. The Brazilian legal system has as its characteristics inquisitorial, accusatory and mixed traits. The questioning is a system by which the two functions of prosecution and trial are presented together in a single organ or a single person, and the adversarial system, the roles are reserved by different persons or bodies. But as noted in the literature, conflicts are presented in the form of interpretation systems. Many authors express their positions, some argue that the system adopted in Brazil is the inquisitorial one, others point to be a mixed system, but others claim to be the adversarial system. Unfortunately, what is observed through the various interpretations presented about the adversarial system, this is still tied to the shackles of inquisitorialism. In recent years, it seems that incessant doctrinal struggles have been waged, as it is possible to the great need of transformations that become urgent. These struggles have important purposes, aimed to search the assertion of criminal procedural law that is guided by constitutional compliance.
\end{abstract}

Keywords: Constitution. Principle Procedure. Adversarial System.

\section{Introdução}

Para melhor compreensão do tema, importante se faz demonstrar a relevância do processo penal que tem como finalidade solucionar juridicamente os conflitos de interesses de forma adequada, seguindo uma sequência de atos, entre esses, a formulação da acusação, a produção das provas, o exercício da defesa e o julgamento da lide.

O sistema processual penal se apresenta em três espécies: acusatório, inquisitivo e misto.

Com relação ao tipo de processo penal "acusatório" diz ser: "contraditório, público, imparcial, assegura ampla defesa; há distribuição das funções de acusar, defender e julgar a órgãos distintos" (CAPEZ, 2006, p. 45). Para Greco Filho (2010, p. 56), este sistema consiste "na separação orgânica entre o órgão acusador e o órgão julgador. Esse se contrapõe ao sistema inquisitivo, em que as funções acusatórias e judicantes se encontram englobadas na mesma pessoa, o juiz".
Nesse sentido, o sistema processual penal utilizado no ordenamento jurídico vem sendo muito discutido no âmbito jurídico. Muitos autores expressam suas posições, uns sustentam que o sistema adotado no Brasil é o inquisitório, outros apontam ser um sistema misto, mas outros afirmam ser o sistema acusatório, apesar de ocorrer que em diversos dispositivos legais se apresenta a atuação do juiz como verdadeiro juiz inquisidor (art. 156, I do CPP).

$\mathrm{O}$ artigo em questão tem como propósito abordar sobre o sistema acusatório e sua forma de ser interpretado na Constituição Federal de 1988. No entanto, para um melhor entendimento é necessária uma síntese do que vem a ser o sistema processual brasileiro que apresenta como características seus traços inquisitórios, acusatórios e misto, e finalizando o estudo se apresenta uma breve conclusão sobre o tema. 


\section{Desenvolvimento}

\subsection{O Processo Penal}

Importante se faz observar sobre a Teoria Geral do Processo que, na atualidade, tem recebido uma inspiração unificadora, como observa Greco Filho (2010, p.1):

o poder jurisdicional, como um dos poderes do Estado, se tornou único, e sua estruturação básica encontra-se em nível da Constituição Federal, de modo que resulta inevitável a conclusão de que há algo comum a toda atividade jurisdicional.

De acordo com o autor, na fase primitiva do direito dos povos, os atos ilícitos não recebiam qualificação específica civil ou penal e eram corrigidos ou reprimidos identicamente (GRECO FILHO, 2010). Com o passar dos tempos, as relações jurídicas foram se tornando complexas, ocorrendo agrupamentos, cada qual com seus próprios princípios e sistemas. E, atualmente, a situação é diferente, no que se refere ao sistema do Direito Processual, a teoria trouxe vários benefícios, mas há muito que se fazer.

Nesse contexto, o Estado, "única entidade dotada de poder soberano, é o titular exclusivo do direito de punir (para alguns, poder-dever de punir)". No entanto, os conflitos só poderão ser solucionados por meio de processo, "sem o processo, não haveria como o Estado satisfazer sua pretensão de punir, nem como o Estado-Jurisdição aplicá-la ou negá-la" (CAPEZ, 2006, p. 1-2).

Portanto, fica compreendido que o processo penal tem a finalidade de solucionar juridicamente os conflitos de interesses de forma adequada "entre o Estado-Administração e o infrator, através de uma sequência de atos que compreendam a formulação da acusação, a produção das provas, o exercício da defesa e o julgamento da lide" (CAPEZ, 2006, p.3). Segundo o autor, para a consecução de seus fins, no processo é necessária a realização de procedimentos direcionados a um provimento final.

A relação processual se diferencia da relação de direito material por meio de elementos identificadores. Estes elementos são citados por Capez (2006), e são esses: sujeitos processuais; objeto da relação processual e pressupostos processuais.

Com relação aos princípios gerais informadores do processo, Capez (2006, p. 3) observa que:

$\mathrm{Na}$ relação processual aplicam-se os chamados princípios constitucionais do processo, garantindo às partes, direitos como o contraditório, a publicidade, o de ser julgado pelo juiz natural da causa, a ampla defesa (no caso do acusado) etc.

Os Princípios constitucionais explícitos do Processo Penal são: Princípio da presunção da inocência ou do estado de inocência ou da situação jurídica de inocência ou da não culpabilidade (art. 50, LVII, CF); Princípio da ampla defesa (art. $5^{\circ}, \mathrm{LV}, \mathrm{CF}$ ), que se divide em autodefesa e defesa técnica; Princípio da igualdade processual ou da paridade das armas - par condítuio (art. 5º caput, CF); Princípio da plenitude da defesa (art. 5, XXXVIII, alínea “a”, CF); Princípio da prevalência do interesse do réu ou favor rei, favor libertatis, in dubio pro reo, favor inocente (art. 5 ${ }^{\circ}$, LVII, CF); Princípio do contraditório ou da bilateralidade da audiência (art. $5^{\circ}, \mathrm{LV}$, $\mathrm{CF}$ ); Princípio do juiz natural (art. 5º LIII, CF); Princípio da publicidade (art. $5^{\circ}$, LX e XXXIII, e art. 93, IX, CF); Princípio da vedação das provas ilícitas (art. $5^{\circ}, \mathrm{LVI}, \mathrm{CF}$ ); Princípios da economia processual, celeridade processual e duração razoável do processo (art. 5, LXXVIII, CF); Princípio constitucional geral do devido processo penal - devido processo legal ou $d u e$ process of Law (art. 5, LIV, CF).

Os Princípios constitucionais implícitos do Processo Penal são: Princípio de que ninguém está obrigado a produzir prova contra si mesmo ou da não autoincriminação (nemo tenetur se detegere); Princípio da iniciativa das partes ou da ação ou da demanda (ne procedat judex ef officio) e princípio consequencial da correlação entre acusação e sentença; Princípio do duplo grau de jurisdição; Princípio do juiz imparcial; Princípio do promotor natural e imparcial ou promotor legal; Princípio da vedação da dupla punição e do duplo processo pelo mesmo fato (ne bis in idem). E ainda, são também implícitos: Princípio da busca da verdade real ou material; Princípio da oralidade e princípios consequenciais da concentração, da imediatidade e da identidade física do juiz; Princípio da comunhão ou aquisição da prova; Princípio do impulso oficial; Princípio da lealdade processual.

De acordo com Greco Filho (2010, p.55), para que ocorra o desenvolvimento e a estruturação do processo penal, “a garantia mais importante e ao redor da qual todo o processo gravita é a da ampla defesa, com os recursos a essa inerentes, sobre a qual convém insistir e ampliar", entendendo dessa forma que o réu tem a possibilidade de argumentar contra a acusação, não deixando exceder os prazos da lei.

Enfim, após essas breves linhas sobre o processo penal se pode adentrar ao tema objeto deste trabalho.

\subsection{Os Sistemas Inquisitivo, Misto e Acusatório: breves linhas}

Na visão de Capez (2006, p. 46), o sistema inquisitivo é considerado "sigiloso, sempre escrito, não é contraditório e reúne na mesma pessoa as funções de acusar, defender e julgar". Para o autor, "o réu é visto nesse sistema como mero objeto da persecução, motivo pelo qual práticas como a tortura eram frequentemente admitidas como meio para se obter a prova-mãe: a confissão".

Na opinião de Fischer (2011, p. 6): "o sistema inquisitivo caracteriza-se por haver concentração em uma mesma pessoa as funções de acusação e julgamento". O autor apresenta a opinião de Andrade (2008, p. 466) a respeito:

ao que se adere, o sistema inquisitivo está formado por dois elementos fixos, que são o princípio inquisitivo e a circunstância de que a abertura do processo poderá ocorrer tanto mediante o oferecimento de uma acusação como de ofício. 
Greco Filho (2010, p. 56) menciona que este sistema inquisitivo "não convém à distribuição da justiça, em virtude do comprometimento do magistrado com a acusação que ele mesmo formulou".

O sistema processual penal misto no dizer de Furlani (2012, p. 1) "é um sistema híbrido ou misto, pois mescla disposições que são oriundas do sistema acusatório e alguns resquícios do sistema inquisitório". Neste tipo de processo penal misto, Capez (2006, p. 46) cita que "há uma frase inicial inquisitiva, na qual se procede a uma investigação preliminar e a uma instrução preparatória, e uma fase inicial, em que se procede ao julgamento com todas as garantias do processo acusatório".

No que concerne ao sistema acusatório, pela relevância do tema neste estudo serão apresentado, no capítulo a seguir, conceitos de autores relacionados, sua evolução no ordenamento jurídico, características e como o sistema se apresenta na Constituição Federal.

\subsection{O Sistema Acusatório}

Dando início ao tema, é necessário demonstrar a diferença entre os sistemas inquisitivo e acusatório; no inquisitivo as funções de acusar e julgar se apresentam unidas em um único órgão ou em uma única pessoa; no sistema acusatório, "tais papéis estariam reservados às pessoas (ou órgãos) distintos" (ANDRADE, 2008).

Em outras palavras, Greco Filho (2010, p.56) cita que este sistema acusatório consiste "na separação orgânica entre o órgão acusador e o órgão julgador. Esse se contrapõe ao sistema inquisitivo, em que as funções acusatórias e judicantes se encontram englobadas na mesma pessoa, o juiz".

No parecer de Capez (2006, p. 45), com relação ao tipo de processo penal acusatório diz ser: "contraditório, público, imparcial, assegura ampla defesa; há distribuição das funções de acusar, defender e julgar a órgãos distintos".

Como explica Oliveira e Fischer (2011, apud FISCHER, 2011, p. 6), este sistema "funda-se na existência de vários sujeitos processuais, tendo eles funções distintas de acusação, defesa e julgamento, sendo certo que a função investigativa só não pode ser atribuída ao julgador". Os autores pontuam que "o Poder Judiciário, em um sistema processual penal acusatório, isto é, em um sistema no qual as funções de acusar (daí acusatório) e de julgar são atribuídas a órgãos distintos, não tem poderes investigatórios".

No entanto antes que se faça um maior aprofundamento do processo acusatório, é necessário explicar como este teve sua evolução histórica.

\subsection{Evolução do Sistema Acusatório}

Furlani (2012, p.1) observa que este sistema acusatório nasceu "na Grécia antiga entre os atenienses e chegou posteriormente aos romanos, quando do surgimento da república".
Nas breves palavras de Khaled Junior (2010, p. 295):

O sistema inquisitório remonta à Inquisição, como a própria nomenclatura claramente indica. Curiosamente, a Inquisição não tinha relação direta com a criminalidade - portanto com a defesa ou retribuição perante o dano ao patrimônio, ou à vida -, mas sim ao desvio em relação aos dogmas estabelecidos pela Igreja, que se viam ameaçados pela proliferação das novas crenças heréticas, no contexto da Reforma religiosa do século XVI. O aparato de repressão inquisitorial apresentava características muito específicas e tinha como fundamentação uma série de verdades absolutas, que giravam em torno do arcabouço ideológico oferecido pelo dogmatismo religioso da época. Sem dúvida, tratava-se de um campo de saber de envergadura considerável, o que pode ser percebido pela existência de um conjunto de técnicas para atingir os fins a que se propunha, reunidas no Manual dos Inquisidores, de Eymerich. [...] O juiz inquisidor atuava como parte, investigava, dirigia, acusava e julgava. Convidava o acusado a declarar a verdade sob pena de coação. Tamanha era a característica persecutória do sistema, que sequer havia constatação de inocência na sentença que eximia o réu, mas um mero reconhecimento de insuficiência de provas para sua condenação. A confissão era entendida como a prova máxima e não havia qualquer limitação quanto aos meios utilizados para extraí-la, visto que eram justificados pela sagrada missão de obtenção da verdade.

O autor explica que através da modernidade, este sistema inquisitório poderia ser superado pelo modelo acusatório: "A exigência de neutralidade no processo de incriminação associou-se, na modernidade, [...], ao desenvolvimento de um direito racional e a centralização no Estado das atribuições da administração da justiça” (KHALED JUNIOR, 2010, p. 297).

$\mathrm{O}$ autor comenta, ainda, que "parte significativa dos processualistas penais afirma que no Brasil vigora um sistema misto, predominantemente considerado como acusatório". E, nessa corrente, para o autor, provavelmente, o nome mais destacado é de Fernando Capez. No entanto, tais processualistas ignoram aspectos de ordem empírica e normativa que desmentem essa caracterização" (KHALED JUNIOR, 2010, p. 300).

Tourinho Filho (2011 apud FURLANI, 2011, p.1) explica que o Brasil adotou este sistema em seguida à promulgação da Carta Magna de 1988, por três fatores: "as funções de acusação foram garantidas ao Ministério Público; a defesa por um advogado ou defensor público foi assegurada a todos os litigantes; e afirmou-se que o julgamento será sempre feito por um juiz natural".

\subsection{Características do Sistema Acusatório}

Na opinião de Souza (2000, p.1), historicamente falando, o que caracteriza o processo acusatório "é a rígida separação entre o juiz e acusador, a imparcialidade, a ampla defesa, o contraditório e, em decorrência, a paridade entre a acusação e a defesa, a publicidade e a oralidade dos atos processuais, entre outros".

o sistema acusatório se caracteriza por contar com dois elementos fixos, que são: o princípio acusatório e o fato de que somente o oferecimento da acusação é que permite o início de seu processo. Os demais elementos invocados pela 
doutrina (p. ex., os princípios da oralidade, contraditório, publicidade e igualdade de armas) são elementos variáveis desse sistema [...] (ANDRADE, 2008).

O autor complementa que, um país ao assumir o sistema acusatório não terá a obrigatoriedade de conferir a responsabilidade ou presidência da investigação criminal ao acusador, e conclui que "o princípio ou regra de que quem acusa investiga se constitui em um elemento variável do sistema acusatório" (ANDRADE, 2008).

Segundo explica Khaled Junior (2010, p.306), o que caracteriza um sistema acusatório:

é a existência de partes e o arbitramento do juiz, que não deveria ir atrás de provas, o que incumbe às referidas partes. A busca pelo verdadeiro não pode suplantar as garantias do réu, pois essa é a característica do processo penal e dos limites que devem ser impostos a busca que ele procede.

Tourinho Filho afirma que o processo acusatório apresenta "traços profundamente marcantes", ou seja, as seguintes características:

a) o contraditório, como garantia político-jurídica do cidadão; b) as partes acusadora e acusada encontram-se no mesmo pé de igualdade;

c) o processo é público;

d) as funções de acusar defender e julgar são atribuídas a pessoas distintas e não é dado ao juiz iniciar o processo sem provocação da parte;

e) o processo pode ser oral ou escrito;

f) existe igualdade de direitos e obrigações entre as partes;

g) a iniciativa do processo cabe à parte acusadora que poderá ser o ofendido, seu representante legal, qualquer cidadão do povo ou o Ministério Público (TOURINHO FILHO, 2011 apud FURLANI, 2011, p. 1).

Com relação a qual sistema vigora no Brasil se observa que não há unanimidade se o sistema processual brasileiro é acusatório, inquisitivo ou misto, porém, leciona Nascimento (2008, p.1), em seu estudo sobre "Processo Penal Brasileiro: Sistema acusatório ou inquisitivo garantista?"

Percebe é a existência de impasses jurídicos no que se refere ao sistema processual penal adotado pelo legislador brasileiro.

\subsection{O Sistema Acusatório na Constituição Federal de 1988}

Os sistemas processuais se apresentam cada qual, com suas próprias características e princípios que os informam. É importante mencionar que a Constituição Federal de 1988, em se tratando do Processo Penal, adota os seguintes princípios: do contraditório; ampla defesa; presunção de inocência; devido processo legal e publicidade dos atos processuais. Através destes princípios a Constituição assegura ao cidadão, o direito de defesa e também de um julgamento justo.

Quando é indicado um crime, o Ministério Público tem a função de promover a ação penal pública, e para o julgamento desta, a autoridade competente é o juiz natural (SAFFRAIDER, 2010).

A acusação é facultada à vítima ou a seus familiares (ação penal privada), mas se torna obrigatória ao Ministério Público quando houver indícios do cometimento de crime: Art. 129. São funções institucionais do Ministério Público: I - promover, privativamente, a ação penal pública, na forma da lei; (...) art. $5^{\circ}$ LIX - será admitida ação privada nos crimes de ação pública, se esta não for intentada no prazo legal.

Assegura a igualdade entre as partes (princípio de equilíbrio de situações ou da paridade de armas):

Art. $5^{\circ}$ Todos são iguais perante a lei, sem distinção de qualquer natureza, garantindo-se aos brasileiros e aos estrangeiros residentes no País a inviolabilidade do direito à vida, à liberdade, à igualdade, à segurança e à propriedade, nos termos seguintes: (BARRETO, 2007, p. 1).

Neste sentido, Saffraider (2010) observa que:

sob o enfoque constitucional poder-se-ia concluir que o sistema adotado no que tange ao processo penal é o sistema acusatório, contudo, ao analisarmos o Código de Processo Penal, há uma clara adoção do sistema inquisitivo, posto que fora concebido em 1941, com influência dos relevos normativos fascistas, onde a preocupação principal é a da busca da verdade real.

Como pode ser observado, o modelo acusatório teve sua consagração na Constituição Federal de 1988, pois ainda que implicitamente, é possível reconhecê-lo em muitos dos dispositivos da Carta Magna (PIMENTEL, 2011, p.1).

Nesse sentido, Fischer (2011, p.3):

Efetivamente, a Constituição ocupa uma função central no sistema vigente, e - não poderia ser diferente - irradia efeitos que precisam ser captados na edição das leis infraconstitucionais. Ousamos dizer que seus comandos maiores se traduzem como ordenadores e dirigentes aos criadores e aos aplicadores (intérpretes) das leis (aí incluída a própria Constituição, por evidente).

Souza (2000, p.1) comenta que é assegurado o sistema acusatório no processo penal pela Constituição Federal, haja vista que:

a. as funções de polícia judiciária e a apuração de infrações penais incumbem às polícias civis e à polícia federal, e inclusive à militar, no que diz respeito aos crimes militares - art. 144 e $\S \S$

b. estabelece o contraditório e a ampla defesa, com o meio e recursos a ela inerentes - art. $5^{\circ}$, inciso LV;

c. a ação penal pública é promovida, privativamente, pelo Ministério Público art. 129, I, embora seja assegurado ao ofendido o direito à ação penal privada subsidiária da pública - art. $5^{\circ}$, LIX;

d. a função de julgar está afeta a juízes constitucionalmente investidos arts. $5^{\circ}$, LIII e 92;

e. assevera a motivação das decisões judiciais - art. 93, IX, e a publicidade dos atos processuais, podendo a lei restringi-la apenas quando a defesa da intimidade ou o interesse público o exigirem - art. $5^{\circ}$, LX.

A autora observa ainda que, "uma gama de recursos na legislação infraconstitucional são garantido às partes" e que "alguns são exclusivos da defesa, como o protesto por novo júri e revisão criminal” (SOUZA, 2000, p. 1).

Ante de fechar este capítulo, Fischer (2011) apresenta, em seus estudos, uma análise comparativa de alguns ordenamentos jurídicos (todos democráticos) mais relevantes do Direito Comparado, salientando que: 
a) na Itália, desde 1989 abandonaram-se os juizados de instrução, cabendo ao Poder Judiciário apenas a supervisão da legalidade da investigação e de tomada de decisões jurisdicionais. O Ministério Público é considerado o verdadeiro responsável pela investigação, que delega para a polícia a realização dos atos;

b) na Alemanha, o Ministério Público é o encarregado das investigações, sendo que seus poderes conferem a possibilidade de realização de buscas domiciliares e interceptações telefônicas (estas apenas em situações de urgência), necessitando de ulterior convalidação pelo Poder Judiciário no prazo de 3 dias;

c) em Portugal, compete ao Ministério Público a direção do inquérito, sendo que à polícia se atribui as funções de coadjuvá-lo na atividade. Também a prática de atos de investigação pela polícia decorre de delegação do Ministério Público (artigo 270 do CPP) 29;

d) no Chile, há expressa disposição no art. $3^{\circ}$ do CPP no sentido de que o Ministério Público dirigirá de forma exclusiva a investigação dos fatos constitutivos do delito, os que determinarem a participação punível e os que possam caracterizar a inocência do imputado, na forma prevista pela Constituição e pela lei;

e) na França, igualmente é o Ministério Público quem dirige (e diretamente) toda a investigação, inclusive no que se refere às prisões cautelares;

f) já nos Estados Unidos, embora com características diversas em três "escalonamentos", o Ministério Público atua nas três fases em que se divide o processo penal: investigatória, judicialização e judicial propriamente dita.

O autor complementa observando que:

Como todos os poderes e instituições estão vinculados a estes paradigmas, especialmente é o Poder Judiciário e o Ministério Público - nos limites dos seus papéis estipulados na Carta Constitucional - quem encontram neles suas funções primordiais, na medida em que têm o dever de dar garantia aos cidadãos (sem descurar da necessária proteção social) diante das eventuais violações que eles virem a sofrer (FISCHER, 2011, p. 5)

Enfim, permanece aberta a questão apresentada por Saffraider (2010) e pela literatura sobre o tema em questão: qual é o sistema adotado no Brasil?Esta questão será respondida no tópico a seguir, no qual serão citadas as várias interpretações apresentadas sobre o sistema acusatório.

\subsection{As Várias Interpretações Apresentadas Sobre o Sistema Acusatório}

Fischer (2011, p.7) inicia esta abordagem comentando:

Desde já deixamos expresso e claro que, segundo nossa leitura, não há previsão expressa na Constituição Federal de 1988 de que o sistema adotado no Brasil seria o acusatório. Mas tal circunstância não impede que, a partir da compreensão (aberta e sistêmica) dos princípios, regras e valores insertos na Carta dirigente, possa ser extraída conclusão que o nosso sistema se pauta pelo princípio acusatório. Com efeito, nos termos do art. 129, I, CF, compete ao Ministério Público promover, privativamente, a ação penal pública. Portanto, o titular da ação penal (ressalvado os casos específicos), de regra, é o parquet. E a função de julgar pertence ao Judiciário, observado o princípio (fundamental) do juiz natural. .

Na opinião do Professor Guilherme de Souza Nucci:

[...] o sistema adotado no Brasil, embora não oficialmente, é o misto", por apresentar dois enfoques: o processual e constitucional. Em outras palavras, se fôssemos seguir exclusivamente o disposto na Constituição Federal poderíamos até dizer que nosso sistema é acusatório (no texto constitucional encontramos os princípios que regem o sistema acusatório). Ocorre que nosso processo penal (procedimentos, recursos, provas, etc.) é regido por Código Específico, que data de 1941, elaborado em nítida ótica inquisitiva (encontramos no CPP muitos princípios regentes do sistema inquisitivo,...). Logo, não há como negar que o encontro dos dois lados da moeda (Constituição e CPP) resultou no hibridismo que temos hoje. Sem dúvida que se trata de um sistema complicado, pois é resultado de um Código de forte alma inquisitiva, iluminado por uma Constituição imantada pelos princípios democráticos do sistema acusatório. Por tal razão, seria fugir à realidade pretender aplicar somente a Constituição à prática forense. Juízes, promotores, delegados e advogados militam contando com um Código de Processo Penal, que estabelece as regras de funcionamento do sistema e não pode ser ignorado como se inexistisse. Essa junção do ideal (CF) com o real (CPP) evidencia o sistema misto (NASCIMENTO, 2008, p.1).

Furlani (2012, p.1) cita que a doutrina majoritária afirma que o sistema é o acusatório, pois neste foram expressamente separadas as funções de acusação, de defesa e de julgamento pela Constituição Federal.

Os apontamentos citados concluem que a atuação do juiz é reduzida, na participação do processo. Melo (2014) explica a respeito:

De fato, no sistema acusatório é diminuída a atuação do juiz, pois este passa a gerenciar o jogo do processo, enquanto o Ministério Público passa a ter o dever de provar efetivamente o que alega, sem o auxílio judicial. Além disso, o sistema acusatório implica na flexibilização da obrigatoriedade da Ação Penal, pois isto permite focar nas provas para delitos mais graves, sendo que atualmente ocorre o contrário, com o sistema policial para manter estatísticas tendendo a focar nos delitos menos graves. Mas José Frederico Marques, nos idos de 1940, logo após o advento do atual Código de Processo Penal, destacava a dificuldade da cultura jurídica brasileira em cumprir o sistema acusatório, conforme consta de sua obra Elementos de Direito Processual Penal. Alguns tentam sustentar que o sistema processual penal no Brasil é misto, portanto uma mistura de acusatório com inquisitivo. Ora, isto é pura retórica. Seria como a moça dizer para o pai que está 'meio grávida', porém, não se tem como estar meio grávida. Ou se está grávida, ou não se está grávida. Da mesma forma o sistema processual penal é inquisito ou é acusatório. No Brasil, o sistema processual é inquisitivo, logo notoriamente inconstitucional.

Na opinião de Herkenhoff (2004, p.128):

uma série de medidas são necessárias para que de tenha uma Justiça melhor e mais popular. De outro lado, na medida em que a intervenção jurídico-penal implica em restrições a direitos fundamentais (como liberdade e patrimônio) sua aplicação sempre deve ocorrer em conformidade com princípios constitucionais penais e processuais penais que se colocam como limite inegociável à incidência do poder punitivo e que, portanto, devem atingir eficácia para evitar os excessos perniciosos - e ilegais - das práticas punitivas inquisitoriais. É nesse sentido que vem sendo travada luta doutrinária incessante nos últimos anos em busca da afirmação de um direito processual penal pautado pela conformidade constitucional e pela exigência de concretização do sistema acusatório que essa conformidade exige. As mudanças são urgentes e não podem mais esperar. Da forma como está, 
fica claro que o sistema permanece preso às amarras do inquisitorialismo, como afirmam Coutinho e Kant de Lima, que chegam à conclusões semelhantes a partir de pressupostos teóricos inteiramente distintos.

Lopes Jr. (2008, p. 6) complementa observando que “o processo não pode mais ser visto como um simples instrumento a serviço do poder punitivo (direito penal), senão que desempenha o papel de limitador do poder e garantidor do indivíduo a ele submetido".

Khaled Jr. (2010, p. 1) reforça:

Afinal, o sistema penal em um Estado Democrático de Direito deve ser um sistema de garantias, onde a resposta penal somente deve surgir a partir da aplicação de um modelo que exclua a arbitrariedade tanto no momento de elaboração da norma quanto no de sua aplicação. Sem dúvida, uma jurisdição como direito fundamental e estruturada em torno do sistema acusatório pode dar aos processos de criminalização, criminação e incriminação outra conotação, para quem sabe ao menos diminuir sensivelmente - a partir de uma perspectiva de redução de danos - a sujeição criminal que tristemente é tão característica dos traços inquisitórios do sistema processual penal brasileiro.

Diante do exposto, e levando em consideração que a atual Constituição consagrou, de forma implícita, o sistema acusatório, separando a função jurisdicional da função acusatória, esta exclusiva do Ministério Público, Melo (2012, p.1) apoia a opinião do renomado doutrinador Andrey Borges de Mendonça:

[...] no sentido de que o magistrado não poder determinar de ofício a realização de prova antecipada antes do início do processo, sob pena de violação ao sistema acusatório, aos princípios da inércia e imparcialidade do juiz e, consequentemente, ao princípio do devido processo legal, vislumbrando, portanto, a inconstitucionalidade parcial do art. 156, I.

Como observado na literatura, além de trazer muita polêmica na doutrina brasileira, o artigo 156 é considerado um dispositivo inconstitucional por vários doutrinadores, por sugerir a presença do juiz inquisidor.

No entanto, segundo opinião de Grinover (1999 apud MELO, 2012), a atuação do magistrado na produção de provas não compromete a imparcialidade, tendo em vista que este não poderia adivinhar o resultado da prova que eventualmente mandou produzir.

\section{Conclusão}

Neste artigo foi proposto abordar sobre o sistema acusatório como princípio processual penal implícito na Constituição Federal. Para melhor compreensão do tema, foi importante demonstrar a importância do processo penal, que tem como finalidade solucionar juridicamente os conflitos de interesses de forma adequada, seguindo uma sequência de atos, entre esses a formulação da acusação, a produção das provas, o exercício da defesa e o julgamento da lide.

Há três sistemas processuais penais: inquisitivo, acusatório e misto. O sistema inquisitivo reúne na mesma pessoa as funções de acusar, de defender e de julgar; o sistema acusatório consiste na separação do órgão acusador e o órgão julgador; e o sistema misto possui características de ambos os outros (inquisitivo e acusatório).

Como observado, o modelo acusatório teve sua consagração na Constituição Federal de 1988, sendo implicitamente reconhecido em alguns dispositivos desta, ou seja, não existe uma previsão expressa na Constituição.

Divergem os autores quanto ao sistema adotado no Brasil. Para alguns, o sistema adotado no país, embora não oficialmente, seja o misto, por apresentar enfoques do sistema inquisitivo na legislação processual ordinária e do sistema acusatório nas normas constitucionais.

Infelizmente, o que se observa pelas várias interpretações apresentadas sobre a legislação processual ordinária é que esta continua presa às amarras do inquisitorialismo. Nestes últimos anos, verifica-se que vêm sendo travadas lutas doutrinárias incessantes, pois se percebe a necessidade de mudanças e que são urgentes. Estas lutas têm propósitos importantes e objetivam a busca da afirmação de um direito processual penal que seja pautado pela conformidade constitucional e pela exigência de concretização do sistema acusatório que essa conformidade exige.

\section{Referencias}

ANDRADE, M.F. Sistemas processuais penais e seus princípios reitores. Curitiba: Juruá, 2008.

BARRETO, J.L. O sistema acusatório e seus requícios inquisitoriais. 2007. Disponível em:

$<$ http://www.artigos.com/artigos/sociais/direito/o--sistema-acusatorio--e---seus---requicios---inquisitoriais.-1652/artigo/\#. U4N7d ldWT8. Acesso em: 20 maio 2020

FISCHER, D. O sistema acusatório brasileiro à luz da constituição federal de 1988 e o PL 156. 2011. Disponível em: $<$ http://www.prrj.mpf.gov.br/custoslegis/revista_2011/2011 Dir_Penal_fischer.pdf $>$. Acesso em: 11 mar. 2020.

FURLANI, D.S. A Constituição Federal brasileira de 1988 e o sistema processual penal adotado. 2012. Disponível em: $<\mathrm{http}: / /$ www.viajus.com.br/viajus.php? pagina $=$ artigos $\& i d=4535>$. Acesso em: 3 maio 2020.

GOMES, L.F. Constitucionalidade dos poderes inquisitivos do juiz. STF abre caminho para juiz político. In: MORAES, A. Os dez anos da Constituição Federal, Temas diversos. São Paulo: Atlas, 1999.

GRINOVER, A.P. A Iniciativa Instrutória do Juiz no Processo Penal Acusatório. Artigo. Revista da Ordem dos Advogados do Brasil, n.68, 1999.

KHALED JR., S.H. O sistema processual penal brasileiro: acusatório, misto ou inquisitório? Civitas, v.10, n.2, p.293-308, 2010.

NASCIMENTO, A.G.A. Processo Penal Brasileiro: Sistema acusatório ou inquisitivo garantista?. Âmbito Jurídico, v.52, 2008. Disponível em: <http://www.ambito-juridico.com.br/site/ index.php?n_link $=\quad$ revista_artigos_leitura\&artigo_id=2690>. Acesso em abrr. 2020.

MELO, A.L.A. Juiz acusador. Brasil precisa abandonar sistema processual penal inquisitivo. 2014. Disponível em:

$<$ http://www.conjur.com.br/2014-jan-13/andre-luis-melo-brasil- 


\section{GARCIA, P.S}

abandonar-sistema-processual-penal-inquisitivo $>$. Acesso em: 20 maio 2020.

MENDONÇA, A.B. Nova reforma do Código de Processo Penal. São Paulo: Método, 2008.

OLIVEIRA, E.P.; FISCHER, D. Comentários ao Código de Processo Penal e sua Jurisprudencia. Rio de Janeiro: Lumen Juris, 2011.

PIMENTEL, J.E.S. A reforma do Código de Processo Penal. Análise crítica ao PL n ${ }^{\circ}$ 156/09 do Senado. Jus Navigandi, v.16, n.2847, p.18 2011.
POZZER, B.R.G. Correlação entre acusação e sentença no processo penal brasileiro. São Paulo: IBCCrim, 2001.

SAFFRAIDER, J.A.. O sistema acusatório no Brasil. JurisWay, 2010. Disponível em: <http://www.jurisway.org.br/v2/dhall. asp?id_dh $=3907>$. Acesso em: 25 maio 2020.

SOUZA, K.M.F. Sistema acusatório e mutatio libelli. (releitura do art. 384, caput, do CPP, face ao ordenamento constitucional). Jus Navigandi, v.5, n.45, 2000.

TOURINHO FILHO, F.C. Manual de processo penal. São Paulo: Saraiva, 2011. 